\title{
Is Innate Memory a Double-Edge Sword in Alzheimer's Disease? A Reappraisal of New Concepts and Old Data
}

\author{
Francesca Salani ${ }^{*}$, Valentina Sterbini, Eleonora Sacchinelli, Mariagrazia Garramone and \\ Paola Bossù
}

Experimental Neuropsychobiology Lab, IRCCS Santa Lucia Foundation, Rome, Italy

An emergent concept in immunology suggests that innate immune system is capable to undergo non-specific long-term responses and to provide resistance by modifying the reactivity to sequential pathogen challenge. This phenomenon, named innate memory, involves epigenetic, and metabolic reprogramming of innate immune cells. Current literature shows that the innate memory process has a mainly beneficial role in host defense, but sometimes can exert detrimental effects, as common in many diseases.

OPEN ACCESS

Edited by:

Niels Hellings,

University of Hasselt, Belgium

Reviewed by:

Silvia Corrochano,

Medical Research Council,

United Kingdom

Yoshiro Ohara,

Kanazawa Medical University, Japan

*Correspondence:

Francesca Salan

f.salani@hsantalucia.it

Specialty section: This article was submitted to

Multiple Sclerosis and

Neuroimmunology,

a section of the journal

Frontiers in Immunology

Received: 18 April 2019

Accepted: 12 July 2019

Published: 07 August 2019

Citation:

Salani F, Sterbini V, Sacchinelli E Garramone $M$ and Bossù $P$ (2019) Is Innate Memory a Double-Edge Sword in Alzheimer's Disease? A Reappraisal

of New Concepts and Old Data.

Front. Immunol. 10:1768

doi: 10.3389/fimmu.2019.01768
Alzheimer's disease (AD) is a progressive neurodegenerative disorder characterized by cognitive decline and dementia. Accumulating findings demonstrate that inflammation is involved in $A D$ pathogenesis and progression and recent genetic and functional data confirm the driving role of the innate immune component in the disease. Furthermore, $A D$ patients show high burden of the most relevant infectious agents and up-regulation of inflammatory features in their innate immune cells, including an activated, or "primed" status of myeloid phagocytic cells in both brain and periphery, resembling trained immunity conditions. Thus, it is conceivable that AD innate cells may be firstly involved in the attempt to resolve recurrent/persistent inflammation but then acquire a trained phenotype mostly unable to maintain the immune regulation, leaving uncontrolled or sometimes supporting the progression of neurodegeneration. The present review aims to summarize evidence evoking innate immune memory mechanisms in $A D$, and to interpret their potential role, either protective or harmful, in disease progression. A better understanding of such mechanisms will provide a fertile ground for development of novel diagnostic, and therapeutic pathways in AD cure.

Keywords: Alzheimer's disease, trained immunity, trained potentiation, trained tolerance, innate immune cells

\section{INTRODUCTION}

Defense is a proper function of the organism that must protect itself from external or internal noxious agents. In vertebrates, as well as in invertebrates and plants, the first protection mechanism is orchestrated by the action of innate immune cells, which cooperate to eliminate hazardous stimula (1). Innate cells are able to fight a broad range of pathogens, although with non-specific responses. They were considered immediate mediators of host resistance and inflammation in contrast with the adaptive lymphocyte-dependent immune response that is antigen specific, and 
capable to provide lifelong protection against re-infection. Over time, it has been repeatedly observed that innate responses induced by exposure to one pathogen or vaccine could affect the following immune response to subsequent encounter of the same pathogen or a different one (2-4). So, the classical vision on innate immune system has been switched into the notion that it also holds a memory (5). Innate cells' memory is not related to gene rearrangements as in lymphocytes, but is a consequence of reprogramming based on gene transcription changes, epigenetic processes, and cellular metabolism (6) addressed to promote a protective response by increasing resistance to reinfection. However, under predisposing conditions, innate memory may endorse human diseases characterized by excessive inflammation, even causing a neuroinflammatory cycle in neuropathological conditions $(7,8)$. Inflammation is a driving force in Alzheimer's disease (AD), a progressive neurodegenerative disease leading to dementia. In particular, genomic studies have associated $\mathrm{AD}$ with dysregulated innate immune cells, and uncontrolled neuroinflammatory processes appear critical contributors in $\mathrm{AD}$ pathogenesis (9-11). Besides alterations in microglia -the brain resident innate immune cells-, blood borne cells, and peripheral inflammatory factors may play a pivotal role in $\mathrm{AD}$ pathogenesis and progression (12). However, the exact mechanisms by which innate cell response influences $\mathrm{AD}$ course is still elusive. Regardless the recent evidence suggesting a role for the innate memory status on neuroinflammation, and neurodegeneration in $\mathrm{AD}$ mice (13), no studies are directly addressed to evaluate innate memory pathways in clinical $\mathrm{AD}$. Main goal of the present mini-review is to recapitulate the features of $\mathrm{AD}$ innate response consistent with a trained phenotype in patients, thus providing insights to better decipher the role of inflammation in the disease.

\section{INNATE IMMUNE MEMORY: CELLS, RECEPTORS AND MECHANISMS}

Innate and adaptive immune responses are components of the host defense integrated system. While innate immunity is considered the first, fast, and non-specific line of defense, adaptive immunity is slower, antigen-specific, and endowed with a memory that makes future responses against the specific antigen more efficient. Innate immune system is composed of different cell types primarily including mononuclear phagocytes as monocytes, macrophages and dendritic cells, but also natural killers (NK), and innate lymphoid cells (ILCs); while B and $\mathrm{T}$ lymphocytes are components of the adaptive system. The primary innate immune cells of the brain are microglia, mononuclear phagocytes that act as sentinel of injuries like macrophages. In adult mice and humans, brain immune cell population is a combination of the resident microglia and other phagocytes, included infiltrated monocytes who differentiate in microglia-like cells, especially during chronic injuries. Microglia have different phenotypes: under normal conditions, when resting have ramified morphology, M1 indicates classically activated, and M2 alternatively activated microglia (14). Recently, a disease-associated microglia (DAM) type has been identified (15).

Recent findings have shown that all cells of the immune system are aware of the immunological experiences and stimuli they are exposed to and have a memory, non-specific in innate and specific in adaptive system. The concept of innate memory has been validated in many innate immune cells with mechanisms that involve epigenetic and metabolic cell remodeling, in contrast to gene rearrangements as in lymphocytes. This phenomenon called trained immunity is a specific immune program triggered by pathogen-derived molecules or other danger stimuli which confers to innate cells a memory. It is a long-lasting altered inflammatory activation, making cells able to respond to subsequent stimulations either more heavily or weakly. These two opposite activities, which are generally balanced for the well-being of the organism, are named trained immunity, and tolerance or, as more recently suggested, trained potentiation and trained tolerance (16).

Actually, memory mechanisms have been well-described for monocytes-macrophages $(6)$ and NK $(17,18)$. Similarly, blood derived DC could be primed by infections, give protection against subsequent challenges showing epigenetic marks $(19,20)$, but their trained immunity features are not fully characterized. Moreover, recent results have shown in mice that microglia are also capable of being trained. In fact, peripherally administration of inflammatory stimuli can alter long-term microglia function, due to differential epigenetic reprogramming that persist during the time influencing neuropathology later in life (13).

As mentioned, epigenetic, and metabolic reprogramming characterize the immune training of innate cells. Changes in histone marks and chromatin architecture are related to an increased, or decreased metabolism and transcriptional processing (21). These mechanisms may be also systemically induced at the level of bone marrow progenitors, and maintained in the daughter cells $(22,23)$, determining a specific status of innate memory that in turn could influence the general inflammatory response.

Cells of the monocyte-macrophage lineage undergo longterm functional reprogramming following activation of patternrecognition receptors (PRRs), that detect infectious pathogenassociated molecular patterns (PAMPs), but also non-infectious damage-associated molecular patterns (DAMPs). Like PAMPs, DAMPs might act as stimuli that activate cells of the innate immune system (24). Exposure to certain PAMPs, as those that bind to toll-like receptors (TLR), and Nod-like receptors (NLR), can confer a type of immunological memory to mononuclear phagocytes that depends on the type of pathogen and its dosage. Thus, activation of NPLR3 inflammasome by PAMPs or DAMPs, promoting the maturation and secretion of IL1 $\beta$ and IL-18, appears as a key mediator in the potentiation process of trained immunity induced by stimuli like BCG, $\beta$-glucan, and Western-type diet $(7,23,25)$. At variance, the bacterial component lipopolysaccharide (LPS) binding to TLR-4, is known to induce tolerance (26). Another study demonstrated that trained potentiation and tolerance are two opposing functional programs, depending on the nature, and concentration of engaged PRRs. Hence, engagement of NLRs (NOD2 or NOD1 
receptors) induces trained potentiation, which can vanish with smaller amounts of ligands, while the engagement of TLRs with high inflammatory doses of PRR ligands induces tolerance. Conversely, low concentrations of TLR ligands in monocytes reverse tolerance to potentiation, heightening the pro-inflammatory state (27).

At first stimulus, epigenetic reprogramming occurs and involves methylation or acetylation on N-terminal histone tails, like $\mathrm{H} 3 \mathrm{~K} 4 \mathrm{me}$, H3K9ac, and H3K27ac. For instance, after $\beta$ glucan treatment, monocytes show enrichment of H3K4me3 in promoters of genes encoding the pro-inflammatory cytokine TNF- $\alpha$, IL-6, and IL-18 (28-30). After stimulation, some epigenetic marks are lost and cells maintain a low inflammatory gene expression. However, some enhancers, called latent enhancer, preserve a state of mono-methylation (H3K4me1) increasing accessibility of chromatin leading to a stronger response to subsequent stimuli (31). After a second stimulus, trained cells show higher inflammatory gene expression and acquire the epigenetic signature on their regulatory regions as $\mathrm{H} 3 \mathrm{~K} 4 \mathrm{me} 3$, H3K4me1, and H3K4ac. After multiple inflammatory stimuli, cells could adopt a tolerance program consisting in the lack of responsiveness, resulting in low expression of proinflammatory cytokines, and acquiring epigenetic markers of transcriptional silencing, as in naïve state (32).

Transcriptional changes also reflect primarily metabolic activation. In monocytes, $\beta$-glucan-induced trained immunity leads changes in cellular metabolism from oxidative phosphorylation to aerobic glycolysis, increasing the ability of innate immune cells to respond to subsequent stimuli (33). In particular, the shift in metabolism leading to increased glycolysis is dependent on the activation of mammalian target of rapamycin (mTOR) through a dectin-1-Akt-HIF-1 $\alpha$ (hypoxia-inducible factor- $1 \alpha$ ) pathway. In addition, the epigenetic changes observed in BCG-trained monocytes are dependent on the induction of the metabolic pathways: if glycolysis or glutaminolysis is inhibited, changes in $\mathrm{H} 3 \mathrm{~K} 4 \mathrm{me} 3$, and $\mathrm{H} 3 \mathrm{~K} 9 \mathrm{me} 3$ at promoter sites of IL-6 and TNF- $\alpha$ reverse, showing a link between these two regulatory cellular processes (34). Metabolic changes influence chromatin remodeling since epigenetic enzymes use small metabolic cofactors to perform their functions, therefore metabolic shift can cause altered epigenetic signature in immune cells (35). During immune memory, immune-metabolism and gene expression are linked by the epigenetic modifications.

\section{ALZHEIMER'S DISEASE AND INNATE IMMUNE CELLS}

The sporadic form of Alzheimer's disease $(A D)$ is the most common type of dementia diagnosed in elderly and its cure or prevention still lacks effective treatments. Main AD histopathologic hallmarks are intracellular neurofibrillary tangles of hyper-phosphorylated tau protein and extracellular aggregates (plaques) of the misfolded amyloid- $\beta$ (A $\beta$ ) peptides (36). A $\beta$ plaques are surrounded by activated glial cells releasing inflammatory mediators, hence the sustained neuroinflammatory response has emerged as a third core pathological feature of $\mathrm{AD}$ (37), with an acknowledged role in disease pathogenesis and evolution $(38,39)$. Accumulation of $\mathrm{A} \beta$, resulting from its imbalanced production and/or clearance, is widely considered a critical pathogenic event that induces microglial activation prompting to a local inflammatory process that in turn leads to amyloid plaque generation. $A \beta$ production may be also connected with antimicrobial response, further strengthening the importance of immune system in AD (40). Genome wide association studies and integrative genomic analyses of brain transcriptomes confirm that myeloid cellspecific immune genes encoding for inflammatory factors and molecules involved in the clearance of misfolded proteins are risk factors for sporadic $\mathrm{AD}(10,41-44)$.

The exact role of microglia underlying $\mathrm{AD}$ onset and progression is still unclear. Generally, microglia hold a protective role as they can sense and clear misfolded proteins, but in $\mathrm{AD}$ they may acquire a dysfunctional phenotype, secreting neurotoxic cytokines, and instigating a persistent inflammatory status $(45,46)$. It might occur in the earliest stages of the disease, while later on microglia and brain-invading monocytes would exert a prevalent beneficial function, triggering a resolution phase, possibly perturbed $(47,48)$. Accordingly, the DAM microglia, identified in the brain of $\mathrm{AD}$ mice and patients, seems to have the potential to restrict neurodegeneration (15). Overall, microglia reactions may be influenced by duration of activation, localization, involvement of other cell types, genetic susceptibility, aging, and disease progression (11), though a PET study suggests that the extent and dynamics of beneficial or detrimental microglia activation vary among patients, rather than depending on disease stages (49). Such view, in addition to explaining the trouble in decoding microglia role in $\mathrm{AD}$, appears in agreement with the potential effects of innate memory response on microglia phenotype (13), which essentially depend on the previous history of exposure to priming factors in each individual.

Inflammation in both brain and periphery may be a very early event in the $\mathrm{AD}$ pathogenic course (37, 50-52). Microglia are able to sense inflammatory signaling molecules originating outside the brain. Peripheral inflammation, as well as activation of blood borne innate immune cells, appears to hold relevant disease-modifying functions in $\mathrm{AD}$ (50, 53, 54). As shown in animal models, blood-derived myeloid cells affect $\mathrm{AD}$-like neurodegeneration with protective, causative, and/or reactive effects, apparently influenced by the disease stage (55-57). Thus, when evaluating the innate cell contribution to $\mathrm{AD}$ pathogenic pathways, both brain resident, and circulating innate immune myeloid cells should be taken into consideration. The latter could participate in the long-lasting dysregulated $\mathrm{AD}$ immune response by acting either directly when recruited to brain, or indirectly through the release of soluble mediators.

The most studied blood borne innate cell populations in $\mathrm{AD}$ are monocytes and macrophages, which enter the brain, and modulate pathology, although with controversial roles (5860 ). Regarding other types of myeloid cells, an involvement in AD neuroinflammation and neurodegeneration is proposed for dendritic cells (DCs) $(61,62)$ and for neutrophils, which could 
cross into the brain parenchyma, and contribute to neuronal damage and cognitive decline (63). Eventually, NK may have some relevance in $\mathrm{AD}$, but their contribution needs to be further clarified $(64,65)$.

Given this scenario, wherein AD progression is likely driven by an interplay of innate cell types, the memory status and capability of these effector cells to respond to neurodegenerative conditions by means of neuroinflammatory modulation is of primary importance to delineate the neuroprotective or damaging consequences of their activities.

\section{EVIDENCE OF INNATE MEMORY PATHWAYS IN AD}

Systemic infections, aging and chronic inflammatory conditions drive innate immune cells to undergo reshaping and they are all well-recognized risk factors of AD. In particular, Herpes simplex virus type 1, Cyto-megalovirus, Chlamydophila pneumoniae, spirochetes, Helicobacter pylori, and periodontal pathogens have been associated with $\mathrm{AD}$, and cognitive decline (66-68). Some of them have been found in $\mathrm{AD}$ patients' brain, listed as causative factors of $\mathrm{AD}$ inflammatory pathways and implicated in disease pathogenesis (69-71). Emergent studies reported a microbial dysbiosis in both $\mathrm{AD}$ animal models and patients, which could affect $A \beta$ amyloidosis and host innate immunity mechanisms (72), leading to a peripheral inflammatory state $(73,74)$. These results support the inflammatory-infectious theory of $\mathrm{AD}(75,76)$. Accordingly, elevated plasma levels of LPS were previously described in AD patients (77) and recently found to progressively accumulate in $\mathrm{AD}$ brain in association with neuropathology, affecting gene expression (78). As reported, infectious stimuli, including bacterial or fungal cells and their components, as well as viruses, are considered potent inducers of innate immune memory, thus the role played by infectious agents in $\mathrm{AD}$ advocates for a reshaping of innate cell response in patients. In addition, complex human diseases with chronic inflammatory components in their etiologies, such as atherosclerosis, arthritis, diabetes and obesity, are predisposing factors for subsequent dementia (79), strengthening the link between a persistent activation of innate response and $\mathrm{AD}$. Finally, aging, the most important risk factor for $\mathrm{AD}$, causes inflammaging (80), a low-grade inflammation characterized by up-regulation of pro-inflammatory mediators and increased response of innate cells, possibly contributing to the pathogenesis of $\mathrm{AD}(81)$.

In keeping with a potentiated trained immunity status of $\mathrm{AD}$ innate cells, several authors have reported elevated levels of circulating pro-inflammatory cytokines and amplified inflammatory response of blood cells in $\mathrm{AD}$ patients. Despite some inconsistent results, meta-analysis studies confirm an overall trend of increased pro-inflammatory cytokines in $\mathrm{AD}$ (82, 83), and higher levels of cytokines were observed in patients with early or mild forms of $\operatorname{AD}(84,85)$. Similarly, peripheral innate cells of AD patients show a "primed" state and the percentage of peripheral monocytes producing pro-inflammatory cytokines increases early in $\mathrm{AD}$ (86). Furthermore, $\mathrm{AD}$ monocytes and
DCs show enhanced inflammatory phenotype in relation with symptom severity (87-89). When the disease progresses to a more severe condition, AD patients show a decrease in the levels of inflammatory markers $(90,91)$. Thus, at variance with the earliest phases, the depressed innate response observed in late stages of $\mathrm{AD}$ might reflect a condition of innate tolerance following repeated and unresolved innate stimulations.

AD microglia also show modifications that remind an adaptive process mediated by trained immunity (92). In fact, in the aging brain and more evidently in $\mathrm{AD}$ patients, microglia appear primed: they are activated, produce increased amounts of pro-inflammatory mediators and are more susceptible to central damage after peripheral insults $(93,94)$. In addition, microglia activation can be suppressed by epigenetic modulation and epigenetic changes occurring during $\mathrm{AD}$ may prime microglia for a later transition to the DAM phenotype $(15,95)$, suggesting that epigenetic mechanisms are important in microglial priming. This picture fits well with what described in an $\mathrm{AD}$ experimental model, where after repeated systemic challenges mimicking bacterial invasion, microglia are epigenetically reprogrammed and, depending on the persistence of triggering, they undergo either a potentiated trained immunity resulting in amplification of pro-inflammatory mediator release or an acquisition of trained tolerance characteristics, both shaping neuropathology (13).

Converging evidence point to PRR activation, histone modifications and metabolic changes of innate cells in $\mathrm{AD}$ progression. Specifically, misfolded proteins like $A \beta$ are able to bind PRRs expressed by microglia and other innate myeloid cells and exert cell activation with resultant release of inflammatory mediators, ultimately contributing to disease progression and severity. $A \beta$, both in its soluble and fibrillary form, is able to bind a variety of receptor molecules promoting inflammation, including CD14, CD36, and TLRs $(96,97)$. It can also act as a DAMP and activate the inflammasome NALP3 that leads to the release of the active pro-inflammatory cytokines IL-1 $\beta$ and IL-18, key components of the innate immune reaction observed in $\mathrm{AD}$ mice brain (98). Consistently, NLRP3 inflammasome activation occurs in the brains of $\mathrm{AD}$ patients, and contributes to pathology in $\mathrm{AD}$ mice (99).

In addition to resulting activated through PRRs engagement, $\mathrm{AD}$ innate cells show changes in cell transcription, epigenetic, and metabolic modifications that are mostly consistent with molecular mechanisms underlying trained immunity. Increased immune activity during AD neurodegeneration appears linked to aging and environmental-driven epigenomic alteration (100) and early epigenetic changes have been described in $\mathrm{AD}$ patients that may contribute to disease pathology (101). For instance, a mis-localization of the epigenetic molecule H3K4me3 between the cell nucleus and the cytoplasm has been reported in early AD (102), though its functional role is still unclear. In $\mathrm{AD}$-mouse model of neurodegeneration, transcriptional and epigenetic changes (including $\mathrm{H} 3 \mathrm{~K} 4 \mathrm{me} 3$ and $\mathrm{H} 3 \mathrm{~K} 27 \mathrm{ac}$ ) have emerged by profiling chromatin state across early and late $\mathrm{AD}$ pathology. Changes in immune genes and regulatory regions during $\mathrm{AD}$-like neurodegeneration in mouse have been found, with strong human-mouse conservation of gene expression, and epigenomic signatures, especially in innate immune cells 
(103). Finally, AD innate cells are likely to undergo a raise of aerobic glycolysis, the metabolic driver of trained immunity. In fact, mTOR signaling is early increased in AD animal models (104), while TREM2-deficient mice with AD-like pathology show defective mTOR signaling, which affects ATP levels and biosynthetic pathways (105). Finally, in AD mouse model, mTOR activation and HIF- $1 \alpha$ signaling, possibly mediated by $A \beta$-induced epigenetic microglial reprogramming, appear unfavorable to AD pathology (13).

\section{POTENTIAL ROLE OF INNATE MEMORY IN AD AND CONCLUDING REMARKS}

Memory status of innate immune cells is governed by the type and concentration of ligand encountered and largely depends on the personal history of exposure to damaging agents during life. Although innate memory's role is mainly protective, it may in some cases influence the course of diseases, especially in those pathological conditions having chronic inflammation as hallmark, like AD. Likely due to many different circumstances, as enhanced infectious burden, microbial dysbiosis and persistence of endogenous misfolded proteins, $\mathrm{AD}$ patients show evidence of innate immunity chronic activation that could lead to maladaptive responses, mainly exacerbating damaging mechanisms in the brain.
Regardless no studies have been addressed yet at evaluating innate memory responses in clinical $\mathrm{AD}$, features of innate immune response in patients and animal models suggest that $\mathrm{AD}$ innate cells, including microglia, monocytes and DCs, may undergo a long-term functional reprogramming characterized by both potentiated and tolerant responses, possibly contributing to disease development. Under this view, we elaborated a schematic representation (Figure 1) according to which peripheral and cerebral innate cells of $\mathrm{AD}$ patients hold a memory of past stimulations that alters brain immune responses to $A \beta$, which in turn accumulates, contributing to the central propagation of pathological changes, and progressive clinical symptoms of $\mathrm{AD}$. Since individuals are exposed to a multiplicity of different threatening and pathogenic agents during their life, a large heterogeneity in innate memory response is expected, in agreement with the high variation of microglia features, and dissimilarities in disease severity and progression among patients. Specifically, trained immunity could have potentiation features at pre-symptomatic and early times of AD progression, being characterized by enhanced release of pro-inflammatory cytokines, increased $\mathrm{A} \beta$ production and damaging consequences on affected brain. In contrast, at $\mathrm{AD}$ later stages, high concentration of persistent stimulus (e.g., A $\beta$ ) could switch the immune response toward trained tolerance. The prolonged exposure to stimulus could bring to desensitization with reduced production of inflammatory cytokines, shifting toward

\section{POTENTIAL ROLE OF INNATE MEMORY IN AD}

GENETIC RISK FACTORS

(APOE, CD33, TREM-2)

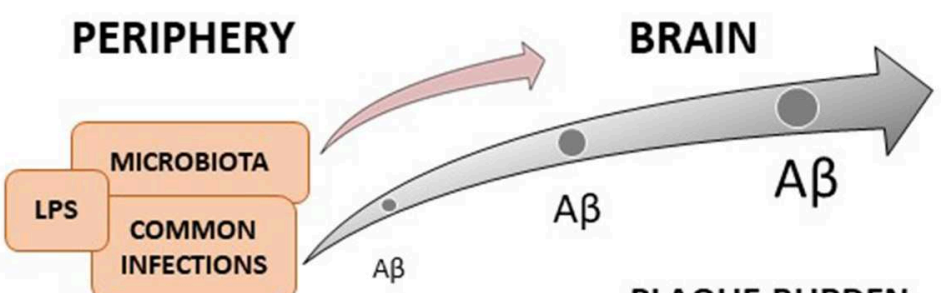

PLAQUE BURDEN
ENVIRONMENTAL RISK FACTORS (CHRONIC INFLAMMATORY CONDITIONS, DIET, AGING)

INNATE MEMORY RESPONSE

\begin{tabular}{|ccc|}
\hline REPEATED TRIGGERING & TRAINED POTENTIATION & TRAINED TOLERANCE \\
\hline PROTECTION & DAMAGE & $\begin{array}{c}\text { RESOLUTION } \\
\text { (MALADAPTIVE) }\end{array}$ \\
\hline PRESYMPTOMATIC PHASE & $\mathrm{MCl}$ & AD
\end{tabular}

FIGURE 1 | The cartoon recapitulates our view of the potential role in AD of innate memory processes occurring during disease progression. A detailed explanation of the drawing is reported in the text. 
maintenance, and repair activities, though possibly inefficacious because of the maladaptive nature of the response.

Future studies should investigate the innate memory status and its specific molecular mechanisms in in vitro models of both peripheral and brain innate cells of $\mathrm{AD}$ patients, especially in relation to disease progression. Accordingly, considering the availability of inhibitors of immune-metabolic and epigenetic pathways leading to trained immunity (7), potential new strategies for $\mathrm{AD}$ treatment could be envisaged. Overall, a better knowledge of innate memory processes in $\mathrm{AD}$ could help in deciphering patients' inflammatory mechanisms underlying pathophysiology and thus facilitating the design of personalized treatments.

\section{REFERENCES}

1. Buchmann K. Evolution of innate immunity: clues from invertebrates via fish to mammals. Front Immunol. (2014) 5:459. doi: 10.3389/fimmu.2014.00459

2. Mackaness GB. The immunology of antituberculous immunity. Am Rev Respir Dis. (1968) 97:337-44.

3. Bistoni F, Vecchiarelli A, Cenci E, Puccetti P, Marconi P and Cassone A. Evidence for macrophage-mediated protection against lethal Candida albicans infection. Infect Immun. (1986) 51:668-74.

4. Aaby P., Kollmann T. R., Benn C. S. (2014). Nonspecific effects of neonatal and infant vaccination: public-health, immunological and conceptual challenges. Nat. Immunol. 15:895-9. doi: 10.1038/ni.2961

5. Netea MG, Quintin J, van der Meer JW. Trained immunity: a memory for innate host defense. Cell Host Microbe. (2011) 9:355-61. doi: 10.1016/j.chom.2011.04.006

6. Netea MG, Joosten LA, Latz E, Mills KH, Natoli G, Stunnenberg HG, et al. Trained immunity: a program of innate immune memory in health and disease. Science. (2016) 352:aaf1098-98. doi: 10.1126/science.aaf1098

7. Arts RJW, Joosten LAB, Netea MG. The potential role of trained immunity in autoimmune and autoinflammatory disorders. Front Immunol. (2018) 9:298. doi: 10.3389/fimmu.2018.00298

8. Salam AP, Borsini A, Zunszain PA. Trained innate immunity: a salient factor in the pathogenesis of neuroimmune psychiatric disorders. Mol Psychiatry. (2018) 23:170-6. doi: 10.1038/mp.2017.186

9. Heneka MT, Carson MJ, El Khoury J, Landreth GE, Brosseron F, Feinstein DL, et al. Neuroinflammation in Alzheimer's disease. Lancet Neurol. (2015) 14:388-405. doi: 10.1016/S1474-4422(15)70016-5

10. Sims R, van der Lee SJ, Naj AC, Bellenguez C, Badarinarayan N, Jakobsdottir J, et al. Rare coding variants in PLCG2, ABI3, and TREM2 implicate microglial-mediated innate immunity in Alzheimer's disease. Nat Genet. (2017) 49:1373-84. doi: 10.1038/ng.3916

11. Sarlus H, Heneka MT. Microglia in Alzheimer's disease. J Clin Invest. (2017) 127:3240-9. doi: 10.1172/JCI90606

12. Cao W, Zheng H. Peripheral immune system in aging and Alzheimer's disease. Mol Neurodegener. (2018) 13:51. doi: 10.1186/s13024-018-0284-2

13. Wendeln AC, Degenhardt K, Kaurani L, Gertig M, Ulas T, Jain G, et al. Innate immune memory in the brain shapes neurological disease hallmarks. Nature. (2018) 556:332-8. doi: 10.1038/s41586-018-0023-4

14. Boche D, Perry VH, Nicoll JA. Review: activation patterns of microglia and their identification in the human brain. Neuropathol Appl Neurobiol. (2013) 39:3-18. doi: 10.1111/nan.12011

15. Keren-Shaul H, Spinrad A, Weiner A, Matcovitch-Natan O, DvirSzternfeld R, Ulland TK, et al. A unique microglia type associated with restricting development of Alzheimer's disease. Cell. (2017) 169:127690. doi: 10.1016/j.cell.2017.05.018

16. Boraschi D, Italiani P. Innate immune memory: time for adopting a correct terminology. Front Immunol. (2018) 9:799. doi: 10.3389/fimmu.2018.00799

17. Sun JC, Beilke JN, Lanier LL. Adaptative immune features of natural killer cells. Nature. (2009) 457:557-61. doi: 10.1038/nature07665

\section{AUTHOR CONTRIBUTIONS}

FS and PB made a substantial, direct, and intellectual contribution to the article designing and wrote the draft. VS, ES, and MG contributed to writing and revising the article. All authors have reviewed and approved the final version of the manuscript for publication.

\section{FUNDING}

This study was supported by the Italian Ministry of Health (CO-2013-02356242) and RC2017/RC2018.

18. Kleinnijenhuis J, Quintin J, Preijers F, Joosten LA, Jacobs C, Xavier RJ, et al. BCG-induced trained immunity in NK cells: role for non-specific protection to infection. Clin Immun. (2014) 155:213-9. doi: 10.1016/j.clim.2014.10.005

19. Burgess SL, Buonomo E, Carey M, Cowardin C, Naylor C, Noor Z, et al. Bone marrow dendritic cells from mice with an altered microbiota provide interleukin 17A-dependent protection against Entamoeba histolytica colitis. MBio. (2014) 5:01817. doi: 10.1128/mBio.01817-14

20. Garber M, Yosef N, Goren A, Raychowdhury R, Thielke A, Guttman M, et al. A high-throughput chromatin immunoprecipitation approach reveals principles of dynamic gene regulation in mammals. Mol Cell. (2012) 47:81022. doi: 10.1016/j.molcel.2012.07.030

21. Seeley JJ, Ghosh S. Molecular mechanisms of innate memory and tolerance to LPS. J Leukoc Biol. (2017) 101:107-19 doi: 10.1189/jlb.3MR0316-118RR

22. Kaufmann E, Sanz J, Dunn JL, Khan N, Mendonça LE, Pacis A, et al. BCG educates hematopoietic stem cells to generate protective innate immunity against tuberculosis. Cell. (2018) 172:176-90.e19. doi: 10.1016/j.cell.2017.12.031

23. Mitroulis I, Ruppova K, Wang B, Chen LS, Grzybek M, Grinenko T, et al. Modulation of myelopoiesis progenitors is an integral component of trained immunity. Cell. (2018) 172:147-61.e12. doi: 10.1016/j.cell.2017.11.034

24. Crişan TO, Netea MG, Joosten LA. Innate immune memory: implications for host responses to damage-associated molecular patterns. Eur J Immunol. (2016) 46:817-28. doi: 10.1002/eji.201545497

25. Christ A, Günther P, Lauterbach MAR, Duewell P, Biswas D, Pelka K, et al. Western diet triggers NLRP3-dependent innate immune reprogramming. Cell. (2018) 172:162-75. doi: 10.1016/j.cell.2017.12.013

26. Fan H, Cook JA. Molecular mechanisms of endotoxin tolerance. J Endotoxin Res. (2004) 10:71-84. doi: 10.1179/096805104225003997

27. Ifrim DC, Quintin J, Joosten LAB, Jacobs C, Jansen T, Jacobs L, et al. Trained immunity or tolerance: opposing functional programs induced in human monocytes after engagement of various pattern recognition receptors. Clin Vaccine Immunol. (2014) 21:534-45. doi: 10.1128/CVI.00688-13

28. Quintin J, Saeed S, Martens JHA, Giamarellos-Bourboulis EJ, Ifrim DC, Logie $\mathrm{C}$, et al. Candida albicans infection affords protection against reinfection via functional reprogramming of monocytes. Cell Host Microbe. (2012) 12:223-32. doi: 10.1016/j.chom.2012.06.006

29. Saeed S, Quintin J, Kerstens HH, Rao NA, Aghajanirefah A, Matarese $\mathrm{F}$, et al. Epigenetic programming of monocyte-to-macrophage differentiation and trained innate immunity. Science. (2014) 345:1251086. doi: $10.1126 /$ science. 1251086

30. Netea MG. Immunological memory in innate immunity. J Innate Immun. (2014) 6:117-8. doi: 10.1159/000357283

31. Ostuni R, Piccolo V, Barozzi I, Polletti S, Termanini A, Bonifacio S, et al. Latent enhancers activated by stimulation in differentiated cells. Cell. (2013) 152:157-71. doi: 10.1016/j.cell.2012.12.018

32. Novakovic B, Habibi E, Wang SY, Arts RJW, Davar R, Megchelenbrink W, et al. $\beta$-Glucan reverses the epigenetic state of LPS-induced immunological tolerance. Cell. (2016) 167:1354-68.e14. doi: 10.1016/j.cell.201 6.09 .034 
33. Cheng SC, Quintin J, Cramer RA, Shepardson KM, Saeed S, Kumar V, et al. mTOR- and HIF-1 $\alpha$-mediated aerobic glycolysis as metabolic basis for trained immunity. Science. (2014) 345:1250684. doi: 10.1126/science. 1250684

34. Arts RJW, Carvalho A, La Rocca C, Palma C, Rodrigues F, Silvestre R, et al. Immunometabolic pathways in BCG-induced trained immunity. Cell Rep. (2016) 17:2562-71. doi: 10.1016/j.celrep.2016.11.011

35. Donohoe DR, Bultman SJ. Metaboloepigenetics: interrelationships between energy metabolism and epigenetic control of gene expression. J Cell Physiol. (2012) 227:3169-77. doi: 10.1002/jcp.24054

36. Hardy J. A hundred years of Alzheimer's disease research. Neuron. (2006) 52:3-13. doi: 10.1016/j.neuron.2006.09.016

37. Kinney JW, Bemiller SM, Murtishaw AS, Leisgang AM, Salazar AM, Lamb BT. Inflammation as a central mechanism in Alzheimer's disease. Alzheimers Dement. (2018) 4:575-90. doi: 10.1016/j.trci.2018.06.014

38. Heppner FL, Ransohoff RM, Becher B. Immune attack: the role of inflammation in Alzheimer disease. Nat Rev Neurosci. (2015) 16:35872. doi: $10.1038 / \mathrm{nrn} 3880$

39. Ransohoff RM. How neuroinflammation contributes to neurodegeneration. Science. (2016) 353:777-83. doi: 10.1126/science.aag2590

40. Kumar DK, Choi SH, Washicosky KJ, Eimer WA, Tucker S, Ghofrani $\mathrm{J}$, et al. Amyloid-b peptide protects against microbial infection in mouse and worm models of Alzheimer's disease. Sci Transl Med. (2016) 8:340ra72. doi: 10.1126/scitranslmed.aaf1059

41. Raj T, Rothamel K, Mostafavi S, Ye C, Lee MN, Replogle JM, et al. Polarization of the effects of autoimmune and neurodegenerative risk alleles in leukocytes. Science. (2014) 344:519-23. doi: 10.1126/science.1249547

42. Jonsson T, Stefansson H, Steinberg S, Jonsdottir I, Jonsson PV, Snaedal J, et al. Variant of TREM2 associated with the risk of Alzheimer's disease. $N$ Engl J Med. (2013) 368:107-16. doi: 10.1056/NEJMoa1211103

43. International Genomics of Alzheimer's Disease Consortium (IGAP). Convergent genetic and expression data implicate immunity in Alzheimer's disease. Alzheimers Dement. (2015) 11:658-71. doi: 10.1016/j.jalz.2014.05.1757

44. Efthymiou AG, Goate AM. Late onset Alzheimer's disease genetics implicates microglial pathways in disease risk. Mol Neurodegener. (2017) 12:43. doi: 10.1186/s13024-017-0184-X

45. Hickman S, Izzy S, Sen P, Morsett L, El Khoury J. Microglia in neurodegeneration. Nat Neurosci. (2018) 21:135969. doi: 10.1038/s41593-018-0242-x

46. Hansen DV, Hanson JE, Sheng M. Microglia in Alzheimer's disease. J Cell Biol. (2018) 217:459-72. doi: 10.1083/jcb.201709069

47. Cuello C. Early and late CNS inflammation in Alzheimer's Disease: two extremes of a continuum? Trends Pharmacol Sci. (2017) 38:95666. doi: 10.1016/j.tips.2017.07.005

48. Whittington RA, Planel E, Terrando N. Impaired resolution of inflammation in Alzheimer's disease: a review. Front Immunol. (2017) 8:1464. doi: 10.3389/fimmu.2017.01464

49. Hamelin L, Lagarde J, Dorothée G, Potier MC, Corlier F, Kuhnast $B$, et al. Distinct dynamic profiles of microglial activation are associated with progression of Alzheimer's disease. Brain. (2018) 14:1855-70. doi: 10.1093/brain/awy079

50. Holmes C, Cunningham C, Zotova E, Woolford J, Dean C, Kerr S, et al. Systemic inflammation and disease progression in Alzheimer disease. Neurology. (2009) 73:768-74. doi: 10.1212/WNL.0b013e3181b6bb95

51. Eikelenboom P, Van Exel E, Hoozemans JJM, Veerhuis R, Rozemuller AJM, Van Gool WA. Neuroinflammation - an early event in both the history and pathogenesis of Alzheimer's disease. Neurodegen Dis. (2010) 7:38-41. doi: 10.1159/000283480

52. Djordjevic J, Sabbir MG, Albensi BC. Traumatic brain injury as a risk factor for Alzheimer's disease: is inflammatory signaling a key player? Curr Alzheimer Res. (2016) 13:730-8. doi: 10.2174/1567205013666160222110320

53. Cunningham C. Microglia and neurodegeneration: the role of systemic inflammation. Glia. (2013) 61:71-90. doi: 10.1002/glia.22350

54. McManus RM, Heneka MT. Role of neuroinflammation in neurodegeneration: new insights. Alzheimers Res Ther. (2017) 9:14. doi: 10.1186/s13195-017-0241-2
55. Simard AR, Soulet D, Gowing G, Julien JP, Rivest S. Bone marrow-derived microglia play a critical role in restricting senile plaque formation in Alzheimer's disease. Neuron. (2006) 49:489-502. doi: 10.1016/j.neuron.2006.01.022

56. Schwartz M, Shechter R. Systemic inflammatory cells fight off neurodegenerative disease. Nat Rev Neurol. (2010) 6:40510. doi: 10.1038/nrneurol.2010.71

57. Sevenich L. Brain-resident microglia and blood-borne macrophages orchestrate central nervous system inflammation in neurodegenerative disorders and brain cancer. Front Immunol. (2018) 9:697. doi: 10.3389/fimmu.2018.00697

58. Fiala M, Zhang L, Gan X, Sherry B, Taub D, Graves MC, et al. Amyloid-beta induces chemokine secretion and monocyte migration across a human blood-brain barrier model. Mol Med. (1998) 4:4809 doi: 10.1007/BF03401753

59. Malm T, Koistinaho M, Muona A, Magga J, Koistinaho J. The role and therapeutic potential of monocytic cells in Alzheimer's disease. Glia. (2010) 58:889-900. doi: 10.1002/glia.20973

60. Prinz M, Priller J. Microglia and brain macrophages in the molecular age: from origin to neuropsychiatric disease. Nat Rev Neurosci. (2014) 15:30012. doi: $10.1038 / \mathrm{nrn} 3722$

61. Bossù P, Spalletta G, Caltagirone C, Ciaramella A. Myeloid dendritic cells are potential players in human neurodegenerative diseases. Front Immunol. (2015) 6:632. doi: 10.3389/fimmu.2015.00632

62. Ciaramella A, Salani F, Bizzoni F, Orfei MD, Caltagirone C, Spalletta G, et al. Myeloid dendritic cells are decreased in peripheral blood of Alzheimer's disease patients in association with disease progression and severity of depressive symptoms. J Neuroinflam. (2016) 13:18. doi: 10.1186/s12974-016-0483-0

63. Zenaro E, Pietronigro E, Della Bianca V, Piacentino G, Marongiu L, Budui S,et al. Neutrophils promote Alzheimer's disease-like pathology and cognitive decline via LFA-1 integrin. Nat Med. (2015) 21:8806. doi: $10.1038 / \mathrm{nm} .3913$

64. Solerte SB, Fioravanti M, Pascale A, Ferrari E, Govoni S, Battaini F. Increased natural killer cell cytotoxicity in Alzheimer's disease may involve protein kinase C dysregulation. Neurobiol Aging. (1998) 19:19199. doi: 10.1016/S0197-4580(98)00050-5

65. Solana C, Tarazona R, Solana R. Immunosenescence of natural killer cells, inflammation, and Alzheimer's disease. Int J Alzheimers Dis. (2018) 2018:3128758. doi: 10.1155/2018/3128758

66. Katan M, Moon YP, Paik MC, Sacco RL, Wright CB, Elkind MS. Infectious burden and cognitive function: the Northern Manhattan Study. Neurology. (2013) 80:1209-15. doi: 10.1212/WNL.0b013e3182896e79

67. Harris SA, Harris EA. Herpes simplex virus type 1 and other pathogens are key causative factors in sporadic Alzheimer's disease. J Alzheimers Dis. (2015) 48:319-53. doi: 10.3233/JAD-142853

68. Bu XL, Yao XQ, Jiao SS, Zeng F, Liu YH, Xiang Y, et al. A study on the association between infectious burden and Alzheimer's disease. Eur J Neurol. (2015) 22:1519-25. doi: 10.1111/ene.12477

69. Sochocka M, Zwolińska K, Leszek J. The infectious etiology of Alzheimer's disease. Curr Neuropharmacol. (2017) 15:9961009. doi: 10.2174/1570159X15666170313122937

70. Eimer WA, Vijaya Kumar DK, Navalpur Shanmugam NK, et al. Alzheimer's disease-associated $\beta$-amyloid is rapidly seeded by Herpes viridae to protect against brain infection. Neuron. (2018) 99:56-63. doi: 10.1016/j.neuron.2018.06.030

71. Dominy SS, Lynch C, Ermini F, Benedyk M, Marczyk A, Konradi A, et al. Porphyromonas gingivalis in Alzheimer's disease brains: evidence for disease causation and treatment with small-molecule inhibitors. Sci Adv. (2019) 5:eaau3333. doi: 10.1126/sciadv.aau3333

72. Shen L, Ji HF. Associations between gut microbiota and Alzheimer's disease: current evidences and future therapeutic and diagnostic perspectives. $J$ Alzheimers Dis. (2019) 68:25-31. doi: 10.3233/JAD-181143

73. Jiang C, Li G, Huang P, Liu Z. The gut microbiota and Alzheimer's disease. Alzheimers Dis. (2017) 58:1-15. doi: 10.3233/JAD-161141

74. Cattaneo A, Cattane N, Galluzzi S, Provasi S, Lopizzo N, Festari C, et al. Association of brain amyloidosis with pro-inflammatory gut bacterial 
taxa and peripheral inflammation markers in cognitively impaired elderly. Neurobiol Aging. (2017) 49:60-8. doi: 10.1016/j.neurobiolaging.2016.08.019

75. Sochocka M, Donskow-Łysoniewska K, Diniz BS, Kurpas D, Brzozowska E, Leszek J. The gut microbiome alterations and inflammation-driven pathogenesis of Alzheimer's disease-a critical review. Mol Neurobiol. (2019) 56:1841-51. doi: 10.1007/s12035-018-1188-4

76. Chiti F, Dobson CM. Protein misfolding, amyloid formation, and human disease: a summary of progress over the last decade. Annu Rev Biochem. (2017) 86:27-68. doi: 10.1146/annurev-biochem-061516-045115

77. Zhang R, Miller RG, Gascon R, Katz J, Lancero $M$, et al. Circulating endotoxin and systemic immune activation in sporadic amyotrophic lateral sclerosis (sALS). J Neuroimmunol. (2009) 206:121-4. doi: 10.1016/j.jneuroim.2008.09.017

78. Zhao Y, Cong L, Lukiw WJ. Lipopolysaccharide (LPS) accumulates in neocortical neurons of Alzheimer's disease (AD) brain and impairs transcription in human neuronal-glial primary co-cultures. Front Aging Neurosci. (2017) 9:407. doi: 10.3389/fnagi.2017.00407

79. Cunningham C, Hennessy E. Co-morbidity and systemic inflammation as drivers of cognitive decline: new experimental models adopting a broader paradigm in dementia research. Alzheimers Res Ther. (2015) 7:33. doi: $10.1186 / \mathrm{s} 13195-015-0117-2$

80. Franceschi C, Capri M, Monti D, Giunta S, Olivieri F, Sevini F, et al. Inflammaging and anti-inflammaging: a systemic perspective on aging and longevity emerged from studies in humans. Mech Ageing Dev. (2007) 128:92105. doi: $10.1016 /$ j.mad.2006.11.016

81. Giunta B, Fernandez F, Nikolic WV, Obregon D, Rrapo E, Town T, et al. Inflammaging as a prodrome to Alzheimer's disease. J Neuroinflammation. (2008) 5:51. doi: 10.1186/1742-2094-5-51

82. Swardfager W, Lanctôt K, Rothenburg L, Wong A, Cappell J, Herrmann N. A meta-analysis of cytokines in Alzheimer's disease. Biol Psychiatry. (2010) 68:930-41. doi: 10.1016/j.biopsych.2010.06.012

83. Su C, Zhao K, Xia H, Xu Y. Peripheral inflammatory biomarkers in Alzheimer's disease and mild cognitive impairment: a systematic review and meta-analysis. Psychogeriatrics. (2019). doi: 10.1111/psyg. 12403

84. Brosseron F, Krauthausen M, Kummer M, Heneka MT. Body fluid cytokine levels in mild cognitive impairment and Alzheimer's disease: a comparative overview. Mol Neurobiol. (2014) 50:534-44. doi: 10.1007/s12035-014-8657-1

85. Popp J, Oikonomidi A, Tautvydaite D, Dayon L, Bacher M, Migliavacca E, et al. Markers of neuroinflammation associated with Alzheimer's disease pathology in older adults. Brain Behav Immun. (2017) 62:20311. doi: $10.1016 /$ j.bbi.2017.01.020

86. Guerreiro RJ, Santana I, Brás JM, Santiago B, Paiva A, Oliveira C. Peripheral inflammatory cytokines as biomarkers in Alzheimer's disease and mild cognitive impairment. Neurodegener Dis. (2007) 4:40612. doi: $10.1159 / 000107700$

87. Bossù P, Ciaramella A, Salani F, Bizzoni F, Varsi E, Di Iulio F, et al. Interleukin-18 produced by peripheral blood cells is increased in Alzheimer's disease and correlates with cognitive impairment. Brain Behav Immun. (2008) 22:487-92. doi: 10.1016/j.bbi.2007.10.001

88. Ciaramella A, Bizzoni F, Salani F, Vanni D, Spalletta G, Sanarico $\mathrm{N}$, et al. Increased pro-inflammatory response by dendritic cells from patients with Alzheimer's disease. J Alzheimers Dis. (2010) 19:55972. doi: 10.3233/JAD-2010-1257

89. Saresella M, Marventano I, Calabrese E, Piancone F, Rainone V, Gatti A, et al. A complex proinflammatory role for peripheral monocytes in Alzheimer's disease. J Alzheimers Dis. (2014) 38:403-13. doi: 10.3233/JAD-131160

90. Sala G, Galimberti G, Canevari C, Raggi ME, Isella V, Facheris $\mathrm{M}$, et al. Peripheral cytokine release in Alzheimer patients: correlation with disease severity. Neurobiol Aging. (2003) 24:909-14. doi: 10.1016/S0197-4580(03)00010-1
91. Motta M, Imbesi R, Di Rosa M, Stivala F, Malaguarnera L. Altered plasma cytokine levels in Alzheimer's disease: correlation with the disease progression. Immunol Lett. (2007) 114:46-51. doi: 10.1016/j.imlet.2007.09.002

92. Haley MJ, Brough D, Quintin J, Allan SM. Microglial priming as trained immunity in the brain. Neuroscience. (2017) 405:4754. doi: 10.1016/j.neuroscience.2017.12.039

93. Perry VH, Newman TA, Cunningham C. The impact of systemic infection on the progression of neurodegenerative disease. Nat Rev Neurosci. (2003) 4:103-12. doi: $10.1038 / \mathrm{nrn} 1032$

94. Perry VH, Holmes C. Microglial priming in neurodegenerative disease. Nat Rev Neurol. (2014) 10:217-24 doi: 10.1038/nrneurol.2014.38

95. Kannan V, Brouwer N, Hanisch UK, Regen T, Eggen BJ, Boddeke HW. Histone deacetylase inhibitors suppress immune activation in primary mouse microglia. J Neurosci Res. (2013) 91:1133-42. doi: 10.1002/j nr. 23221

96. Stewart CR, Stuart LM, Wilkinson K, van Gils JM, Deng J, Halle A, et al. CD36 ligands promote sterile inflammation through assembly of a toll-like receptor 4 and 6 heterodimer. Nat Immunol. (2010) 11:15561. doi: $10.1038 /$ ni. 1836

97. Liu Y, Walter S, Stagi M, Cherny D, Letiembre M, Schulz-Schaeffer W, et al. LPS receptor (CD14): a receptor for phagocytosis of Alzheimer's amyloid peptide. Brain. (2005) 128:1778-89. doi: 10.1093/brain/awh531

98. Halle A, Hornung V, Petzold GC, Stewart CR, Monks BG, Reinheckel T, et al. The NALP3 inflammasome is involved in the innate immune response to amyloid-beta. Nat Immunol. (2008) 9:857-65. doi: 10.1038/ni.1636

99. Heneka MT, Kummer MP, Stutz A, Delekate A, Schwartz S, Vieira-Saecker A, et al. NLRP3 is activated in Alzheimer's disease and contributes to pathology in APP/PS1 mice. Nature. (2013) 493:674-8. doi: 10.1038/nature11729

100. Benayoun BA, Pollina EA, Brunet A. Epigenetic regulation of ageing: linking environmental inputs to genomic stability. Nat Rev Mol Cell Biol. (2015) 16:593-610. doi: $10.1038 / \mathrm{nrm} 4048$

101. Liu X, Jiao B, Shen L. The epigenetics of Alzheimer's disease: factors and therapeutic implications. Front Genet. (2018) 9:579. doi: 10.3389/fgene.2018.00579

102. Mastroeni D, Delvaux E, Nolz J, Tan Y, Grover A, Oddo S, et al. Aberrant intracellular localization of $\mathrm{H} 3 \mathrm{k} 4 \mathrm{me} 3$ demonstrates an early epigenetic phenomenon in Alzheimer's disease. Neurobiol Aging. (2015) 36:31219. doi: 10.1016/j.neurobiolaging.2015.08.017

103. Gjoneska E, Pfenning AR, Mathys H, Quon G, Kundaje A, Tsai LH, et al. Conserved epigenomic signals in mice and humans reveal immune basis of Alzheimer's disease. Nature. (2015) 518:365-9. doi: 10.1038/nature14252

104. Wang C, Yu JT, Miao D, Wu ZC, Tan MS, Tan L. Targeting the mTOR signaling network for Alzheimer's disease therapy. Mol Neurobiol. (2014) 49:120-35. doi: 10.1007/s12035-013-8505-8

105. Ulland TK, Song WM, Huang SC, Ulrich JD, Sergushichev A, Beatty WL, et al. TREM2 maintains microglial metabolic fitness in Alzheimer's disease. Cell. (2017) 170:649-63.e13. doi: 10.1016/j.cell.2017.07.023

Conflict of Interest Statement: The authors declare that the research was conducted in the absence of any commercial or financial relationships that could be construed as a potential conflict of interest.

Copyright (๑) 2019 Salani, Sterbini, Sacchinelli, Garramone and Bossù. This is an open-access article distributed under the terms of the Creative Commons Attribution License (CC BY). The use, distribution or reproduction in other forums is permitted, provided the original author(s) and the copyright owner(s) are credited and that the original publication in this journal is cited, in accordance with accepted academic practice. No use, distribution or reproduction is permitted which does not comply with these terms. 